\title{
Utility of multilevel lateral interbody fusion of the thoracolumbar coronal curve apex in adult deformity surgery in combination with open posterior instrumentation and L5-S1 interbody fusion: a case-matched evaluation of 32 patients
}

\author{
Alexander A. Theologis, MD, ${ }^{1}$ Gregory M. Mundis Jr., MD, ${ }^{2}$ Stacie Nguyen, MPH, ${ }^{2}$ \\ David O. Okonkwo, MD, PhD, ${ }^{3}$ Praveen V. Mummaneni, MD, ${ }^{4}$ Justin S. Smith, MD, PhD, ${ }^{5}$ \\ Christopher I. Shaffrey, MD, ${ }^{5}$ Richard Fessler, MD, ${ }^{6}$ Shay Bess, MD, ${ }^{7}$ Frank Schwab, MD, ${ }^{8}$ \\ Bassel G. Diebo, MD, ${ }^{9}$ Douglas Burton, MD, ${ }^{10}$ Robert Hart, MD, ${ }^{11}$ Vedat Deviren, MD, ${ }^{1}$ and \\ Christopher Ames, MD, ${ }^{4}$ for the International Spine Study Group
}

\begin{abstract}
${ }^{1}$ Department of Orthopaedic Surgery, University of California, San Francisco; ${ }^{2}$ Department of Orthopaedic Surgery, San Diego Center for Spinal Disorders, La Jolla, California; ' ${ }^{3}$ Department of Neurological Surgery, University of Pittsburgh, Pennsylvania; ${ }^{4}$ Department of Neurologic Surgery, University of California, San Francisco, California; ${ }^{5}$ Department of Neurosurgery, University of Virginia Medical Center, Charlottesville, Virginia; ${ }^{6}$ Department of Neurosurgery, Rush University Medical Center, Chicago, Illinois; ' ${ }^{7}$ Department of Orthopaedic Surgery, Rocky Mountain Hospital for Children, Denver, Colorado; ${ }^{8}$ Department of Orthopedic Surgery, NYU Hospital for Joint Diseases; 'Department of Orthopaedic Surgery, NYU Langone Medical Center, New York, New York; ${ }^{10}$ Department of Orthopedic Surgery, University of Kansas Medical Center, Kansas City, Kansas; and ${ }^{11}$ Department of Orthopedic Surgery, Oregon Health \& Science University, Portland, Oregon
\end{abstract}

\begin{abstract}
OBJECTIVE The aim of this study was to evaluate the utility of supplementing long thoracolumbar posterior instrumented fusion (posterior spinal fusion, PSF) with lateral interbody fusion (LIF) of the lumbar/thoracolumbar coronal curve apex in adult spinal deformity (ASD).

METHODS Two multicenter databases were evaluated. Adults who had undergone multilevel LIF of the coronal curve apex in addition to PSF with L5-S1 interbody fusion (LS+Apex group) were matched by number of posterior levels fused with patients who had undergone PSF with L5-S1 interbody fusion without LIF (LS-Only group). All patients had at least 2 years of follow-up. Percutaneous PSF and 3-column osteotomy (3CO) were excluded. Demographics, perioperative details, radiographic spinal deformity measurements, and $\mathrm{HRQOL}$ data were analyzed.

RESULTS Thirty-two patients were matched (LS+Apex: 16; LS: 16) (6 men, 26 women; mean age $63 \pm 10$ years). Overall, the average values for measures of deformity were as follows: Cobb angle $>40^{\circ}$, sagittal vertical axis (SVA) $>6 \mathrm{~cm}$, pelvic tilt $(\mathrm{PT})>25^{\circ}$, and mismatch between pelvic incidence $(\mathrm{PI})$ and lumbar lordosis $(\mathrm{LL})>15^{\circ}$. There were no significant intergroup differences in preoperative radiographic parameters, although patients in the LS+Apex group had greater Cobb angles and less LL. Patients in the LS+Apex group had significantly more anterior levels fused (4.6 vs 1), longer operative times (859 vs 379 minutes), and longer length of stay (12 vs 7.5 days) (all $p<0.01$ ). For patients in the LS+Apex group, Cobb angle, pelvic tilt (PT), lumbar lordosis (LL), PI-LL (lumbopelvic mismatch), Oswestry Disability Index (ODI) scores, and visual analog scale (VAS) scores for back and leg pain improved significantly $(p<0.05)$. For patients in the LS-Only group, there were significant improvements in Cobb angle, ODI score, and VAS scores for back and leg pain. The LS+Apex group had better correction of Cobb angles ( $56 \%$ vs $33 \%, p=0.02$ ), SVA ( $43 \%$ vs $5 \%, p=0.46)$, LL (62\% vs $13 \%, p=0.35)$, and PI-LL ( $68 \%$ vs $33 \%, p=0.32)$. Despite more LS+Apex patients having major complications $(56 \%$
\end{abstract}

\footnotetext{
ABBREVIATIONS ALIF = anterior lumbar interbody fusion; $A S A=$ American Society of Anesthesiologists; $A S D=$ adult spinal deformity; $B M I=$ body mass index; CCI = Charlson Comorbidity Index; EBL = estimated blood loss; HRQoL = health-related quality of life; LIF = lateral interbody fusion; LL = lumbar lordosis; LOS = length of stay; $\mathrm{ODI}=$ Oswestry Disability Index; $\mathrm{PI}=$ pelvic incidence; $\mathrm{PI}-\mathrm{LL}=$ mismatch between $\mathrm{PI}$ and LL (lumbopelvic mismatch); PSF = posterior instrumented spinal fusion; PT = pelvic tilt; SVA = sagittal vertical axis; TK = thoracic kyphosis; TLIF = transforaminal lumbar interbody fusion; VAS = visual analog scale; 3CO = 3-column osteotomy. SUBMITTED December 27, 2015. ACCEPTED August 3, 2016.
}

INCLUDE WHEN CITING Published online October 21, 2016; DOI: 10.3171/2016.8.SPINE151543. 
vs $13 \% ; p=0.02$ ) and postoperative leg weakness ( $31 \%$ vs $6 \%, p=0.07$ ), there were no intergroup differences in 2-year outcomes.

CONCLUSIONS Long open posterior instrumented fusion with or without multilevel LIF is used to treat a variety of coronal and sagittal adult thoracolumbar deformities. The addition of multilevel LIF to open PSF with L5-S1 interbody support in this small cohort was often used in more severe coronal and/or lumbopelvic sagittal deformities and offered better correction of major Cobb angles, lumbopelvic parameters, and SVA than posterior-only operations. As these advantages came at the expense of more major complications, more leg weakness, greater blood loss, and longer operative times and hospital stays without an improvement in 2-year outcomes, future investigations should aim to more clearly define deformities that warrant the addition of multilevel LIF to open PSF and L5-S1 interbody fusion.

https://thejns.org/doi/abs/10.3171/2016.8.SPINE151543

KEY WORDS adult spinal deformity; lateral interbody fusion; minimally invasive; lumbosacral interbody fusion; complications; health-related quality of life

\section{$\mathrm{L}$} UMBAR/thoracolumbar scoliosis is a common feature of adult spinal deformity (ASD) and is frequently accompanied by global spinal malalignment, back and leg pain, and decreased quality of life. Operative intervention for ASD has proven cost effective compared with nonoperative management, ${ }^{25}$ as many patients have persistent pain and curve progression with nonoperative treatment..$^{27,29,37}$ Keys to achieving good postoperative outcomes include correction of scoliosis, decompression of neural elements, avoidance of pseudarthrosis, and restoration/maintenance of global spinal alignment.

Traditionally, anterior spinal fusion with instrumentation of the lumbar/thoracolumbar curve was most common, as it provided excellent deformity correction and high patient satisfaction. ${ }^{12,17,18,30,37}$ However, complications associated with traditional open anterior lumbar approaches led to increasing popularity of alternative and less-invasive anterior approaches. Since its first report, ${ }^{24}$ the minimally invasive, lateral, transpsoas approach (lateral interbody fusion, LIF) has proved safe and effective for deformity correction when combined with posterior instrumented spinal fusion (posterior spinal fusion, PSF) in ASD. 1,5,8,16,26,33,36 However, the utility of combining long PSF with multilevel LIF of the primary lumbar/thoracolumbar curve apex in ASD has not been defined. The objective of this study was to compare perioperative complications, radiographic deformity parameters, and healthrelated quality of life (HRQoL) scores of patients with ASD treated with PSF and lumbosacral interbody fusion (L5-S1) with or without LIF of the lumbar/thoracolumbar curve apex.

\section{Methods \\ Patient Population}

Two multicenter databases were retrospectively reviewed. The first database included ASD patients who underwent traditional open operations (not minimally invasive surgery) and were enrolled prospectively. The second database included ASD patients who had previously undergone operations that included a minimally invasive approach; their data were retrospectively entered into the database. Institutional review board approval was obtained at each participating center. All eligible patients were older than 18 years and had at least one of the fol- lowing: scoliosis $\geq 20^{\circ}$, sagittal vertical axis $($ SVA) $\geq 5$ $\mathrm{cm}$, pelvic tilt $(\mathrm{PT}) \geq 25^{\circ}$, or thoracic kyphosis $(\mathrm{TK}) \geq 60^{\circ}$.

Adults in the aforementioned databases who had undergone open PSF and L5-S1 interbody fusion and had at least 2 years of follow-up and complete preoperative and postoperative radiographic and clinical outcome data were included. Patients treated with stand-alone LIF, percutaneous PSF, posterior-only PSF without any interbody fusion, 3-column osteotomy (3CO), anterior column release, ${ }^{10,11,22,34}$ and anterior lumbar interbody fusion (ALIF) or transforaminal lumbar interbody fusion (TLIF) used at any interspace cranial to the L5-S1 interspace were excluded so as to minimize variations of the surgical techniques that might have confounded the results. Patients who underwent L5-S1 ALIF were positioned supine, while lateral decubitus positioning was used for those undergoing TLIF. Data on the timing of ALIF in relation to posterior instrumentation/fusion were not available for analysis. Data for types of interbody cages (i.e., lordotic vs straight) at each level were also not available for analysis.

Two groups were defined based on whether or not treatment included multilevel LIF of the coronal curve apex. The first group (from the first database) consisted of patients who underwent PSF and L5-S1 interbody fusion, and is referred as the LS-Only group (Fig. 1). The second group (from the second database) consisted of patients who first underwent multilevel LIF (minimum 2 levels) (Stage 1) followed by PSF and L5-S1 interbody fusion (Stage 2), and is referred to as the LS+Apex group (Fig. 2). Groups were matched based on the number of posterior vertebral levels fused so as to avoid confounding, as this parameter has been shown to be a strong predictor of complications, independent of age or presence of comorbidities. ${ }^{16}$ Patients were matched by assigning a propensity score using linear regression. Scores were ranked and then divided into 3 groups with similar propensity scores. To create an equal sample size from both groups, a random sample of the larger group was used. There were no significant differences in levels fused posteriorly between the 2 groups (confirmed by Mann-Whitney U-test).

\section{Outcome Parameters}

Patient demographics, clinical characteristics, and surgical details included age, sex, body mass index (BMI), 

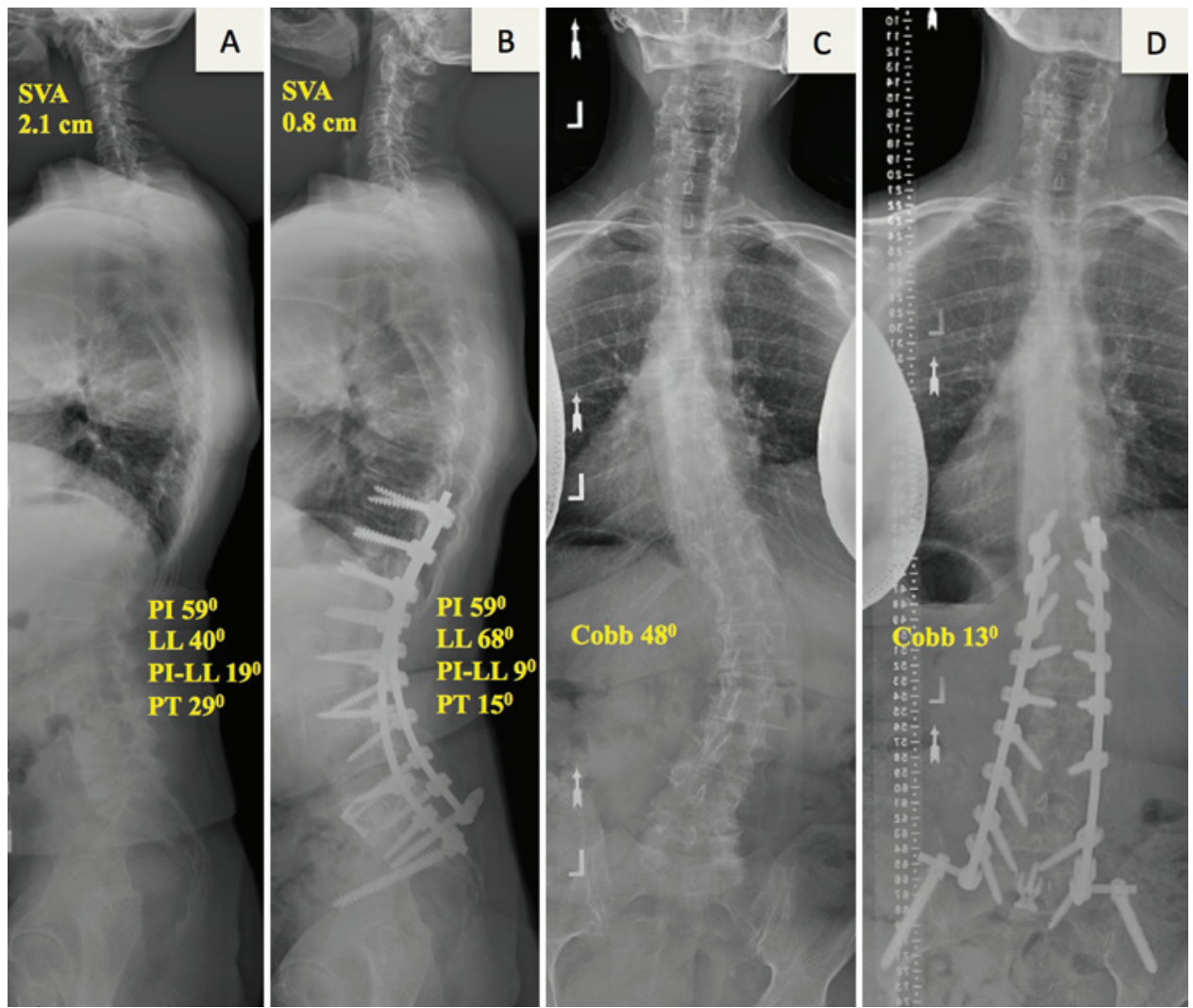

FIG. 1. Representative preoperative (A and $\mathbf{C}$ ) and postoperative (B and $\mathbf{D})$ radiographs of a patient in the LS-Only group. This 56-year-old woman with moderate degenerative scoliosis and spinopelvic sagittal imbalance underwent staged L5-S1 ALIF and T-10 to pelvis open posterior spinal instrumented fusion. The radiographs obtained at 2 years' follow-up (B and D) show significant improvements in LL, PI-LL, PT, and major Cobb angles. Figure is available in color online only.

Charlson Comorbidity Index (CCI), American Society of Anesthesiologists (ASA) physical status classification (converted to an Arabic numeral for purposes of analysis), estimated blood loss (EBL), operative time, number of anterior and posterior levels fused, levels at which LIF procedures were used, type of L5-S1 interbody fusion (ALIF or TLIF), and hospital length of stay (LOS). Postoperative complications were divided into major and minor, as described by Carreon et al. ${ }^{6}$

Radiographic analysis was performed on preoperative and 2-year follow-up standing, 36-inch radiographs. All measurements were performed using Spineview (ENSAM Laboratory of Biomechanics) at a central location and included global C7-S1 SVA, lumbar lordosis (LL), pelvic incidence (PI), PT, mismatch between PI and LL (PI-LL), and lumbar/thoracolumbar Cobb angle.

Clinical outcome measures included the Oswestry Disability Index $(\mathrm{ODI})^{13}$ and pre- and postoperative back and leg pain as assessed with a 10-point visual analog scale (VAS).

\section{Statistical Analysis}

Frequency distributions and summary statistics were tabulated for all baseline and outcome variables. Mean values are given with standard deviations. Categorical variable distributions were compared using the Fisher exact or Pearson chi-square test depending on sample and cell sizes. Perioperative continuous variables were compared using paired Student t-tests within each group, while continuous variables at each time-point between each group were compared using unpaired Student t-tests.

\section{Results}

Of 1215 patients enrolled, 32 were matched (16 in each group, LS+Apex and LS-Only; 6 men and 26 women; mean age $63 \pm 10$ years). The large exclusion is a result of stringent inclusion criteria (only L5-S1 interbody fusion, no $3 \mathrm{CO}$, and case matching based on the number of posterior levels fused) and highlights the difficulty of comparing like populations for a tremendously heterogeneous disorder and associated surgical strategies.

Patient demographic and operative data are presented in Table 1. The entire cohort had an average BMI $<30$, mean CCI of 1.8, and mean ASA classification of 2.4. The LS-Only and LS+Apex groups were similar with regard to age, sex, BMI, CCI, and ASA classification. An average of 10 levels were fused and instrumented posteriorly in the overall cohort; there was no statistically significant intergroup difference in the number of levels fused, as anticipated from matching. With regard to L5-S1 interbody fusion, TLIF was used more commonly ( $>90 \%$ of cases) than ALIF in both groups. The distribution of ALIF and 


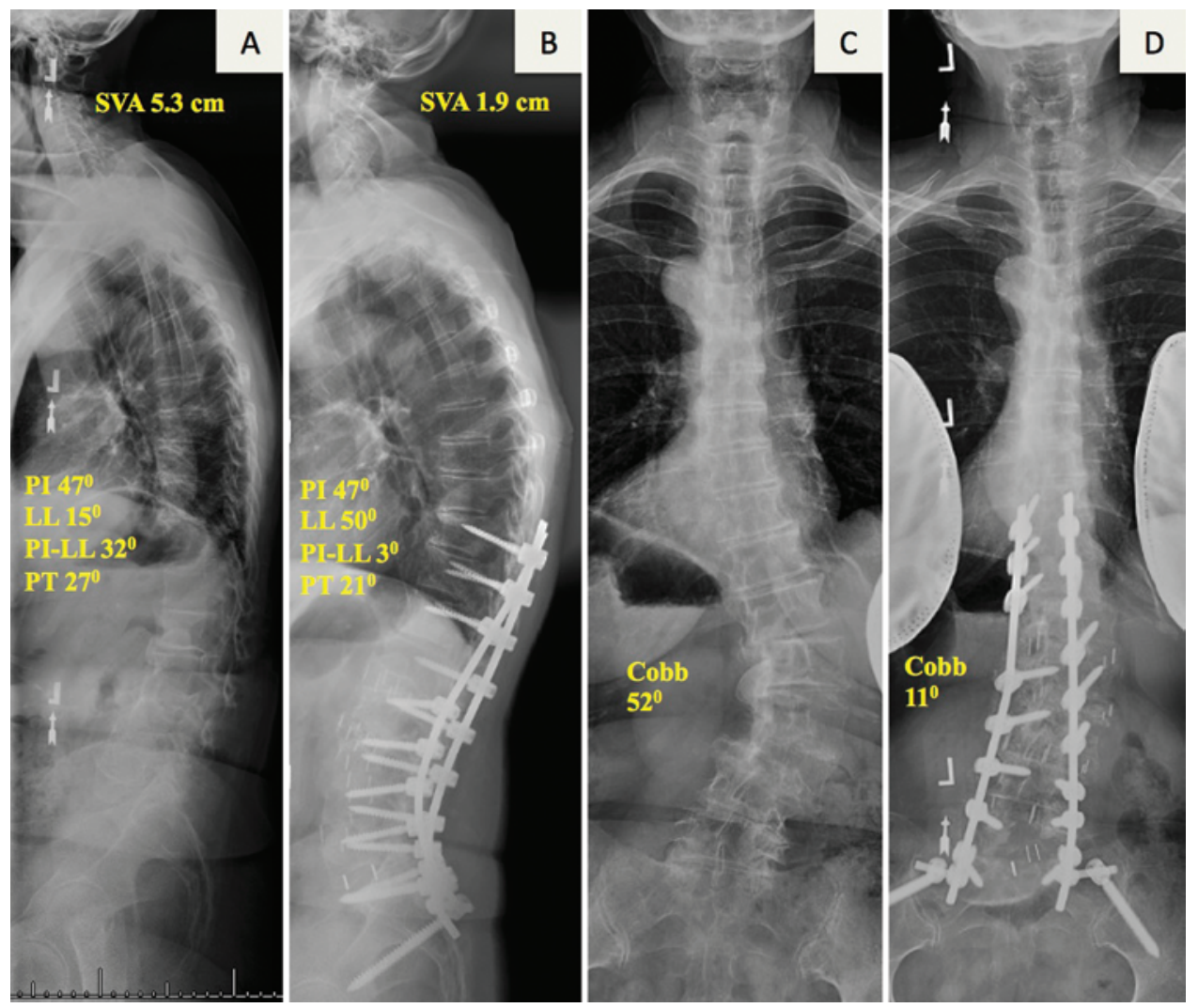

FIG. 2. Representative preoperative (A and $\mathbf{C}$ ) and postoperative (B and $\mathbf{D})$ radiographs of a patient in the LS+Apex group. This 75 -year-old woman with moderate degenerative scoliosis and spinopelvic sagittal imbalance underwent staged L1-5 LIF and T-10 to pelvis open posterior spinal instrumented fusion with L5-S1 TLIF. The radiographs obtained at 2 years' follow-up (B and D) show significant improvements in LL, PI-LL, SVA, PT, and major Cobb angles. Figure is available in color online only.

TLIF procedures was similar in the 2 groups. Fifty-four LIF procedures were performed in the LS+Apex group (average 3.4 per case). The most common levels at which LIF procedures were performed were L2-3 (29.6\%), L3-4 $(27.8 \%)$, and L4-5 (25.9\%). No LIFs were performed proximal to T-12. Operative times averaged nearly 600 minutes for all cases, with patients in the LS+Apex group having significantly longer times (480 minutes longer on average) than those in the LS-Only group $(\mathrm{p}<0.01)$. The LOS was significantly longer in the LS+Apex group (average 4.5 days) as well $(\mathrm{p}<0.01)$.

Results of radiographic analysis are presented in Table 2. Preoperatively, for the entire cohort, the average lumbar/thoracolumbar Cobb angle was $43^{\circ}$, the mean SVA was greater than $6 \mathrm{~cm}$, and the mean PI-LL was $20^{\circ}$. Patients in the LS+Apex group had greater Cobb angles $\left(49^{\circ}\right.$ vs $\left.36^{\circ}, \mathrm{p}=0.06\right)$ and less LL $\left(27^{\circ}\right.$ vs $\left.41^{\circ}, \mathrm{p}=0.06\right)$; all other preoperative radiographic parameters were similar in the 2 groups (Table 2). At 2 years' follow-up, the mean Cobb angle, PT, LL, and PI-LL were significantly lower than preoperative values in the LS+Apex group. In the LS-Only group, only the Cobb angle showed statistically significant improvement; the postoperative SVA, LL, PI-LL, and PT values were not significantly different from preoperative values. Radiographic parameters that remained persistently abnormal after operation in the LSOnly group were SVA (mean $6.1 \mathrm{~cm}$ ), PT (mean $24.2^{\circ}$ ), and PI-LL $\left(11.0^{\circ}\right)$. Compared with the LS-Only group, patients in the LS+Apex group had better correction of Cobb angles, SVA, PT, LL, and PI-LL.

Postoperative complications are presented in Table 3. Of 32 patients whose data were analyzed, 16 patients (50\%) had a complication. There were no statistically significant differences between the 2 groups with respect to the percentages of patients who required revision operations and had minor complications. Significantly more patients in the LS+Apex group had a major complication (56\% vs $12.5 \%$ in the LS-Only group, $\mathrm{p}=0.02$ ). Patients in the LS+Apex group had more leg weakness $(31.3 \%$ vs $6.3 \%, p=0.17$ ), and more minor radiographic complications $(25 \%$ vs $0 \%, \mathrm{p}=0.11)$ than patients in the LS-Only group. All infections in the LS+Apex group were associated with posterior incisions; no lateral incisions became infected. There were no differences in pseudarthrosis rates between the 2 groups $(6.3 \%$ in each group, $p>0.99$ ).

Clinical outcome data are presented in Table 4. Preoperatively, most of the patients were severely disabled (ODI score $>40$ ), and there was no statistically significant difference in mean ODI scores for the 2 groups $(50.5 \pm 1.7$ for the LS+Apex group vs $43.4 \pm 16.2$ for the LS-Only group, $\mathrm{p}=0.23$ ). Most patients had severe back pain preoperatively (VAS score $>8$ ), and the mean VAS scores for back pain were similar in the 2 groups $(p=0.91)$. Most of the patients had moderate leg pain preoperatively, and the 
TABLE 1. Patient demographic and clinical characteristics and operative data

\begin{tabular}{|c|c|c|c|c|}
\hline Variable & All & LS+Apex Group & LS-Only Group & $p$ Value \\
\hline No. of pts & 32 & 16 & 16 & $>0.99$ \\
\hline Age & $63.0 \pm 10.3$ & $64.0 \pm 10.0$ & $62.1 \pm 10.9$ & 0.62 \\
\hline Sex & & & & 0.33 \\
\hline Male & 6 & 4 & 2 & \\
\hline Female & 26 & 12 & 14 & \\
\hline BMI & $26.0 \pm 5.7$ & $24.4 \pm 4.9$ & $27.7 \pm 6.1$ & 0.11 \\
\hline $\mathrm{CCl}$ & $1.8 \pm 2.7$ & $2.2 \pm 3.2$ & $1.4 \pm 2.1$ & 0.67 \\
\hline ASA score* & $2.4 \pm 0.7$ & $2.6 \pm 0.5$ & $2.1 \pm 0.7$ & 0.08 \\
\hline \multicolumn{5}{|c|}{ Mean no. of levels fused } \\
\hline Posterior & $10.0 \pm 4.7$ & $10.8 \pm 3.3$ & $9.1 \pm 5.8$ & 0.47 \\
\hline Anterior & $2.8 \pm 2.0$ & $4.6 \pm 1.1$ & $1.0 \pm 0$ & $<0.001$ \\
\hline \multicolumn{5}{|l|}{ LIF } \\
\hline T12-L1 & 2 & 2 & NA & NA \\
\hline L1-2 & 7 & 7 & NA & NA \\
\hline L2-3 & 16 & 16 & NA & NA \\
\hline L3-4 & 15 & 15 & NA & NA \\
\hline$\llcorner 4-5$ & 14 & 14 & NA & NA \\
\hline L5-S1 interbody & & & & 0.189 \\
\hline ALIF & 2 & 1 & 1 & \\
\hline TLIF & 27 & 15 & 12 & \\
\hline OR time (minutes) & $590 \pm 287$ & $859.1 \pm 194.8$ & $379.1 \pm 141.4$ & $<0.01$ \\
\hline $\mathrm{EBL}(\mathrm{ml})$ & $1946 \pm 1289$ & $2460.0 \pm 1405.2$ & $1992.9 \pm 1539.9$ & 0.294 \\
\hline LOS (days) & $9.2 \pm 4.1$ & $12.1 \pm 4.7$ & $7.5 \pm 2.8$ & $<0.01$ \\
\hline
\end{tabular}

$\mathrm{NA}=$ not applicable; OR = operating room; pt = patient.

* The ASA physical status classification was converted to an Arabic numeral score for purposes of data analysis.

VAS scores for leg pain were also similar in the 2 groups $(\mathrm{p}=0.30)$. Postoperatively, there were significant improvements in ODI and VAS scores for back and leg pain in both groups. In turn, the mean 2-year postoperative ODI and VAS scores for back and leg pain were significantly lower than preoperative values for both groups. Postoperative improvements in ODI scores and VAS scores for back and leg pain were similar in the 2 groups.

\section{Discussion}

Circumferential fusion has traditionally been advocated for large lumbar/thoracolumbar curves and global spinal malalignment, as it provides higher fusion rates, greater deformity correction, and better clinical outcomes than posterior-only techniques. ${ }^{15,23,37}$ The lateral, transpsoas approach is an attractive option for achieving interbody fusion in ASD, as it provides minimally invasive access to the lumbar spine/thoracolumbar junction and is associated with less blood loss, avoids direct neural manipulation, and puts less physiological stress on patients compared with multilevel ALIF and TLIF., $928,35,36,38$

The goal of this investigation was to evaluate the utility of supplementing long thoracolumbar open PSF with multilevel LIF of the lumbar/thoracolumbar curve apex in ASD. As each deformity and associated operation is unique, this study was designed to isolate effects of LIF on 2-year postoperative outcomes by case-matching patients so that like operative strategies, save the presence of the multilevel LIF procedures (i.e., all patients had L5S1 interbody fusion, open posterior instrumentation, and no 3CO), were compared. In turn, sample sizes are small. Deformities are variable as well, given the undefined role of LIF in ASD. As such, this is a unique investigation, as it is the first cohort analysis of its kind. Previous studies regarding LIF in the setting of ASD have been primarily case series. $1,2,5,8,19,35,36$

The major advantage of multilevel LIF in our patients was radiographic. While the average Cobb angle magnitudes improved significantly in both groups, correction was significantly better with LIF (average $28^{\circ}$ for the LS+Apex group vs $12^{\circ}$ for the LS-Only group). This is consistent with previous reports on multilevel LIF in ASD..$^{1,5,16,33,35}$ For example, Caputo et al. found a $72 \%$ improvement in Cobb angles (preoperative $20.2^{\circ}$ vs postoperative $5.6^{\circ}$ )..$^{5}$ Wang et al. also reported significant improvement in Cobb angles (preoperative mean $31.4^{\circ}$ vs postoperative mean $11.4^{\circ}$ ) in their study involving 23 patients with ASD who underwent multilevel LIF (average 3.7 levels per case). ${ }^{35}$ In a separate study of ASD patients treated with LIF at an average of 3 levels per case, Dakwar et al. demonstrated an average $15^{\circ}$ Cobb angle improvement (preoperative $21.3^{\circ}$ vs postoperative $\left.6.1^{\circ}\right) .^{8}$ Interestingly, 2 patients in their series had preoperative Cobb angles of $48^{\circ}$ and $49^{\circ}$, which improved to $8^{\circ}$ and $12^{\circ}$, respectively, after undergoing T12-L5 LIF procedures. ${ }^{8}$ In Tormenti and colleagues' series of 8 ASD patients (mean preoperative Cobb angle $38.9^{\circ}$ ) treated with multilevel minimally invasive LIF 


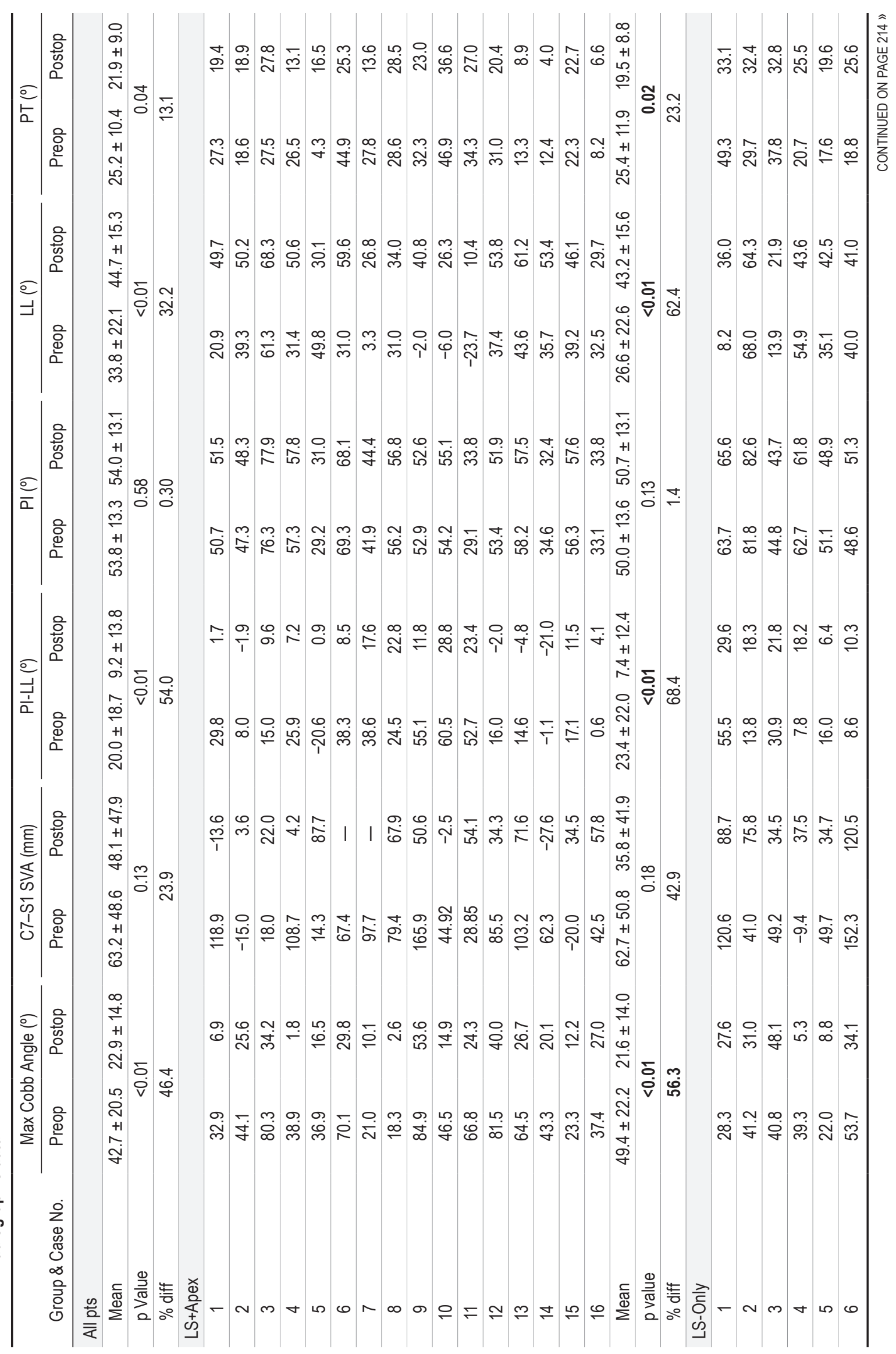




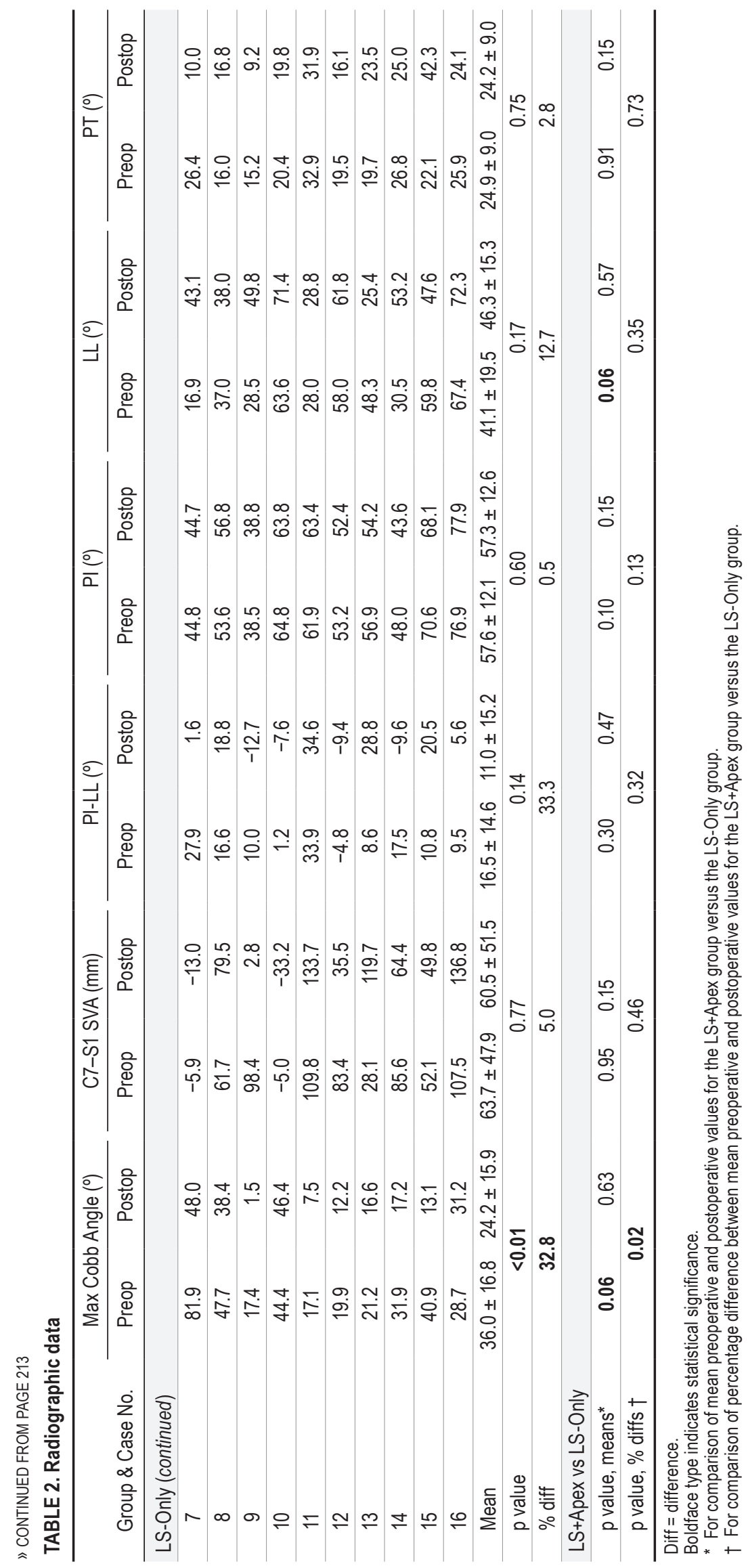


TABLE 3. Complications

\begin{tabular}{|c|c|c|c|c|c|c|}
\hline \multirow[b]{2}{*}{ Complication } & \multirow{2}{*}{$\begin{array}{l}\text { All Pts } \\
(n=32)\end{array}$} & \multicolumn{2}{|c|}{ LS+Apex Group $(n=16)$} & \multicolumn{2}{|c|}{ LS-Only Group ( $n=16)$} & \multirow{2}{*}{$\begin{array}{c}p \\
\text { Value }\end{array}$} \\
\hline & & No. of Pts $(\%)$ & Case No. & No. of Pts (\%) & Case No. & \\
\hline Any & $16(50.0 \%)$ & $11(68.8 \%)$ & $1,3,4,5,8,9,10,12,13,14,16$ & $5(31.3 \%)$ & $2,6,9,11,15$ & 0.08 \\
\hline Reoperation & $5(15.6 \%)$ & $4(25.0 \%)$ & $1,4,5,8$ & $1(6.3 \%)$ & 6 & 0.34 \\
\hline Major & $11(34.4 \%)$ & $9(56.3 \%)$ & $1,2,4,8,9,10,12,13,16$ & $2(12.5 \%)$ & 2,6 & 0.02 \\
\hline Death & $0(0.0 \%)$ & $0(0.0 \%)$ & & $0(0.0 \%)$ & & $>0.99$ \\
\hline Blindness & $0(0.0 \%)$ & $0(0.0 \%)$ & & $0(0.0 \%)$ & & $>0.99$ \\
\hline Cardiopulmonary & $0(0.0 \%)$ & $0(0.0 \%)$ & & $1(6.3 \%)$ & 2 & $>0.99$ \\
\hline DVT & $2(6.3 \%)$ & $1(6.3 \%)$ & 10 & $1(6.3 \%)$ & 2 & $>0.99$ \\
\hline PE & $1(3.1 \%)$ & $1(6.3 \%)$ & 10 & $0(0.0 \%)$ & & $>0.99$ \\
\hline Implant failure & $2(6.3 \%)$ & $2(12.5 \%)$ & 4,8 & $0(0.0 \%)$ & & 0.48 \\
\hline Neurological & $6(18.8 \%)$ & $5(31.3 \%)$ & $1,9,10,12,16$ & $1(6.3 \%)$ & 6 & 0.17 \\
\hline Infection & $3(9.4 \%)$ & $3(18.8 \%)$ & $1,2,13$ & $0(0.0 \%)$ & & 0.23 \\
\hline Sepsis & $0(0.0 \%)$ & $0(0.0 \%)$ & & $0(0.0 \%)$ & & $>0.99$ \\
\hline Stroke & $0(0.0 \%)$ & $0(0.0 \%)$ & & $0(0.0 \%)$ & & $>0.99$ \\
\hline Vascular & $0(0.0 \%)$ & $0(0.0 \%)$ & & $0(0.0 \%)$ & & $>0.99$ \\
\hline Visceral & $0(0.0 \%)$ & $0(0.0 \%)$ & & $0(0.0 \%)$ & & $>0.99$ \\
\hline Wound dehiscence & $0(0.0 \%)$ & $0(0.0 \%)$ & & $0(0.0 \%)$ & & $>0.99$ \\
\hline Pseudarthrosis & $2(6.3 \%)$ & $1(6.3 \%)$ & 1 & $1(6.3 \%)$ & 6 & $>0.99$ \\
\hline PJF & $2(6.3 \%)$ & $1(6.3 \%)$ & 14 & $1(6.3 \%)$ & 6 & $>0.99$ \\
\hline Minor & $15(46.9 \%)$ & $7(43.8 \%)$ & $1,3,4,5,8,13,16$ & $7(43.8 \%)$ & & $>0.99$ \\
\hline Infection & $3(9.4 \%)$ & $2(12.5 \%)$ & 1,16 & $1(6.3 \%)$ & 15 & 0.54 \\
\hline Wound & $1(3.1 \%)$ & $0(0.0 \%)$ & & $1(6.3 \%)$ & 5 & $>0.99$ \\
\hline Implant & $1(3.1 \%)$ & $1(6.3 \%)$ & 1 & $0(0.0 \%)$ & & $>0.99$ \\
\hline Radiographic & $4(12.5 \%)$ & $4(25.0 \%)$ & $3,4,5,8$ & $0(0.0 \%)$ & & 0.11 \\
\hline Neurological & $0(0.0 \%)$ & $0(0.0 \%)$ & & $0(0.0 \%)$ & & $>0.99$ \\
\hline Delirium & $0(0.0 \%)$ & $0(0.0 \%)$ & & $0(0.0 \%)$ & & $>0.99$ \\
\hline Cardiopulmonary & $2(6.3 \%)$ & $1(6.3 \%)$ & 13 & $1(6.3 \%)$ & 2 & $>0.99$ \\
\hline Vascular & $0(0.0 \%)$ & $0(0.0 \%)$ & & $0(0.0 \%)$ & & $>0.99$ \\
\hline $\mathrm{GI}$ & $5(15.6 \%)$ & $1(6.3 \%)$ & 5 & $4(25.0 \%)$ & $2,9,11,15$ & 0.33 \\
\hline Renal & $0(0.0 \%)$ & $0(0.0 \%)$ & & $0(0.0 \%)$ & & $>0.99$ \\
\hline Intraop & $2(6.3 \%)$ & $2(12.5 \%)$ & 1,3 & $0(0.0 \%)$ & & 0.48 \\
\hline
\end{tabular}

DVT = deep vein thrombosis; $\mathrm{GI}$ = gastrointestinal; $\mathrm{PE}=$ pulmonary embolism; $\mathrm{PJF}=$ proximal junctional failure.

(mean 2.8 levels per patient) and open PSF, the postoperative average Cobb angle was $13.4^{\circ} .{ }^{33}$ In their comparative group, consisting of 4 patients who underwent posterioronly instrumentation combined with posterior interbody fusion at a variable number of levels (ranging from none to 3 levels), the mean values for curve correction were lower than in patients treated with the combination of minimally invasive LIF and open PSF. ${ }^{33}$

Regional sagittal alignment is not consistently changed after use of LIF. ${ }^{1,5,8,20,33}$ Caputo et al. found global LL decreased from $10.1^{\circ}$ to $9.2^{\circ}$ after multilevel LIF and posterior instrumentation. ${ }^{5}$ Tormenti et al. noted a decrease in LL from $47.3^{\circ}$ preoperatively to $41.8^{\circ}$ postoperatively. ${ }^{33}$ Conversely, Wang et al. noted an $8^{\circ}$ improvement in LL (preoperative $37.4^{\circ}$ vs postoperative $45.5^{\circ}$ ) after LIF and percutaneous PSF. ${ }^{35}$ Furthermore, one-third of patients did not have correction of sagittal plane imbalance in the series by Dakwar et al. ${ }^{8}$ These data contrast with our data showing that the patients in our LS+Apex group had sig- nificant improvements in LL (average $17^{\circ}$ ), PI-LL (preoperative $23^{\circ}$ vs postoperative $7^{\circ}$ ), PT (average $6^{\circ}$ ), and SVA (average $2.7 \mathrm{~cm}$ ). While these improvements may have been afforded by the open posterior approach, our patients who underwent a posterior-only approach did not have significantly different 2-year values for SVA, PT, LL, and PI-LL compared with preoperative values. Although our LS-Only group had a normal mean LL value $\left(46^{\circ}\right) 2$ years postoperatively, the mean SVA $(6.1 \mathrm{~cm})$, pelvic tilt $\left(24^{\circ}\right)$, and PI-LL $\left(11^{\circ}\right)$ values were persistently abnormal 2 years after surgery. This may have been due to small sample size or may suggest that optimal deformity correction was not maintained when LIF procedures were not performed.

Despite superior radiographic deformity correction, addition of multilevel LIF to PSF was associated with longer operative times, more EBL, and longer LOS. Specifically, the average operative time for the LS+Apex group was 859 minutes, which was 480 minutes longer than for the LSOnly group. This difference was not only attributable to 
TABLE 4. HRQoL outcome data

\begin{tabular}{|c|c|c|c|c|c|c|}
\hline \multirow{2}{*}{$\begin{array}{c}\text { Group \& } \\
\text { Case No. }\end{array}$} & \multicolumn{2}{|c|}{ ODI } & \multicolumn{2}{|c|}{ VAS Back } & \multicolumn{2}{|c|}{ VAS Leg } \\
\hline & Preop & Postop & Preop & Postop & Preop & Postop \\
\hline \multicolumn{7}{|l|}{ All pts } \\
\hline Mean & $46.9 \pm 16.6$ & $30.4 \pm 17.8$ & $8.1 \pm 1.5$ & $3.4 \pm 2.6$ & $5.6 \pm 3.0$ & $2.2 \pm 2.3$ \\
\hline$p$ value & \multicolumn{2}{|c|}{$<0.01$} & \multicolumn{2}{|c|}{$<0.01$} & \multicolumn{2}{|c|}{$<0.01$} \\
\hline$\%$ diff & \multicolumn{2}{|c|}{33.7} & \multicolumn{2}{|c|}{58.1} & \multicolumn{2}{|c|}{48.9} \\
\hline \multicolumn{7}{|l|}{ LS+Apex } \\
\hline 1 & 52.0 & 38.0 & 9.0 & 9.0 & 5.0 & 0.0 \\
\hline 2 & 46.0 & 22.0 & 9.0 & 2.0 & 8.0 & 3.0 \\
\hline 3 & 46.0 & 42.2 & 10.0 & 5.0 & 10.0 & 5.0 \\
\hline 4 & 64.4 & 60.0 & 7.0 & 1.0 & 6.0 & 0.0 \\
\hline 5 & 48.9 & 52.5 & 8.0 & 7.0 & 6.0 & 5.0 \\
\hline 6 & 36.0 & 10.0 & 8.0 & 1.0 & 8.0 & 1.0 \\
\hline 7 & 52.0 & 42.0 & 10.0 & 5.0 & 8.0 & 3.0 \\
\hline 8 & 66.7 & 55.0 & 8.0 & 3.0 & 5.0 & 2.0 \\
\hline 9 & 64.0 & 14.0 & 7.0 & 1.0 & 9.0 & 1.0 \\
\hline 10 & 46.0 & 36.0 & 8.0 & 2.0 & 2.0 & 2.0 \\
\hline 11 & 85.1 & 28.0 & 8.0 & 4.0 & 8.0 & 4.0 \\
\hline 12 & 8.9 & 6.0 & 6.0 & 0.0 & 0.0 & 0.0 \\
\hline 13 & 54.0 & 52.0 & 8.0 & 2.0 & 1.0 & 0.0 \\
\hline 14 & 44.0 & 26.0 & 8.0 & 6.0 & 8.0 & 0.0 \\
\hline 15 & 36.0 & 38.0 & 7.0 & 4.0 & 6.0 & 0.0 \\
\hline 16 & 58.0 & 34.0 & 9.0 & 3.0 & 9.0 & 3.0 \\
\hline Mean & $50.5 \pm 16.7$ & $34.7 \pm 16.2$ & $8.1 \pm 1.1$ & $3.4 \pm 2.5$ & $6.2 \pm 3.0$ & $1.8 \pm 1.8$ \\
\hline$p$ value & \multicolumn{2}{|c|}{$<0.01$} & \multicolumn{2}{|c|}{$<0.01$} & \multicolumn{2}{|c|}{$<0.01$} \\
\hline$\%$ diff & \multicolumn{2}{|c|}{29.7} & \multicolumn{2}{|c|}{59.1} & \multicolumn{2}{|c|}{65.3} \\
\hline \multicolumn{7}{|l|}{ LS-Only } \\
\hline 1 & 32.0 & 12.0 & 4.0 & 2.0 & 5.0 & 6.0 \\
\hline 2 & 38.0 & 0.0 & 7.0 & 0.0 & 2.0 & 0.0 \\
\hline 3 & 12.0 & 8.0 & 7.0 & 8.0 & 6.0 & 2.0 \\
\hline 4 & 52.0 & 0.0 & 10.0 & 0.0 & 0.0 & 0.0 \\
\hline 5 & 30.0 & 58.0 & 8.0 & 0.0 & 8.0 & 7.0 \\
\hline 6 & 26.0 & 8.0 & 8.0 & 0.0 & 0.0 & 1.0 \\
\hline 7 & 48.0 & 24.0 & 7.0 & 2.0 & 7.0 & 0.0 \\
\hline 8 & 72.0 & 22.0 & 10.0 & 1.0 & 8.0 & 4.0 \\
\hline 9 & 64.0 & 54.0 & 9.0 & 8.0 & 0.0 & 0.0 \\
\hline 10 & 38.0 & 18.0 & 5.0 & 3.0 & 5.0 & 2.0 \\
\hline 11 & 42.0 & 28.0 & 8.0 & 5.0 & 4.0 & 6.0 \\
\hline 12 & 52.0 & 40.0 & 8.0 & 3.0 & 6.0 & 3.0 \\
\hline 13 & 64.0 & 54.0 & 8.0 & 6.0 & 8.0 & 5.0 \\
\hline 14 & 50.0 & 36.0 & 10.0 & 4.0 & 7.0 & 6.0 \\
\hline 15 & 50.0 & 32.0 & 10.0 & 5.0 & 9.0 & 0.0 \\
\hline 16 & 24.0 & 22.0 & 10.0 & 7.0 & 6.0 & 0.0 \\
\hline Mean & $43.4 \pm 16.2$ & $26.0 \pm 18.7$ & $8.1 \pm 1.8$ & $3.4 \pm 2.9$ & $5.1 \pm 3.0$ & $2.6 \pm 2.7$ \\
\hline$p$ value & \multicolumn{2}{|c|}{$<0.01$} & \multicolumn{2}{|c|}{$<0.01$} & & \\
\hline$\%$ diff & & & & & & \\
\hline LS+Apex vs LS-Onl & n-groups con & son) & & & & \\
\hline$p$ value, means ${ }^{*}$ & 0.23 & 0.17 & 0.91 & 0.95 & 0.30 & 0.32 \\
\hline$p$ value, $\%$ diffs $\dagger$ & & & & & & \\
\hline
\end{tabular}


Boldface values indicate statistical significance.

* For comparison of mean preoperative and postoperative values for the LS+Apex group versus the LS-Only group.

$\dagger$ For comparison of percentage difference between mean preoperative and postoperative values for the LS+Apex group versus the LS-Only group.

patients who had a third surgery (i.e., ALIF) for L5-S1 interbody support. Also, the average LOS was 4.5 days longer in the LS+Apex group. These findings are not unexpected, as performing a separate lateral operation is a second surgery that is often performed in a staged manner relative to the posterior approach. Even if it is not staged, a single-day operation that involves an ALIF procedure (supine), multilevel LIF procedures (lateral decubitus), and a posterior approach would require substantial operative time (as was the case for 1 patient in our series). The average EBL was $500 \mathrm{ml}$ greater in the LS+Apex group than in the LS-Only group. This is consistent with the literature in that lateral interbody fusions are associated with minimal blood loss. ${ }^{8,16,19,26,35}$ However, the average EBL for both cohorts in our study was approximately $2 \mathrm{~L}$, a degree of blood loss that has been correlated with overall complication rates in spine surgery. ${ }^{6,16}$

The overall complication rate in our cohort was high and reflects the complexity of these operations in elderly patients whose cases are medically complex. It is also consistent with previously reported complication rates (as high as $80 \%$ ) after operations for ASD. ${ }^{7,9,14}$ The use of open PSF in both groups may have contributed to the high complication rate. In Isaac and colleagues' series of 107 patients treated with LIF, the incidence of any complication $(27.9 \%$ vs $15.4 \%)$ and the incidence of major complications $(20.7 \%$ vs 5.8\%) were both higher in patients who had open PSF than in those who had percutaneous PSF ${ }^{16}$ Interestingly, all of the reoperations and deep wound infections in that study were associated with open PSF, ${ }^{16}$ which was also the case in our study.

While performing posterior fusion procedures via a percutaneous approach may result in fewer complications, the overall complication rate after LIF in patients with degenerative scoliosis ranges from $6.1 \%$ to $33.6 \%{ }^{16,19,26,36}$ Reported approach-related complications for LIF include: wound dehiscence, major vessel injury, kidney lacerations, ileus, bowel injury, gastric volvulus, pleural cavity violation, incisional hernias, psoas weakness, and motor and sensory lumbar plexus nerve palsies. ${ }^{5,8,16,26,33,35}$ While no patient in either of our cohorts suffered a vascular or visceral injury, significantly more of the patients in the LS+Apex group had a major complication. While only 1 patient in the LSOnly group had a new neurological deficit postoperatively, $5(31.3 \%)$ of the patients in the LS+Apex group had a new postoperative motor deficit, radiculopathy, or nerve palsy. This is consistent with previous reports. For example, in Wang and colleagues' study of 26 ASD patients treated with multilevel LIF, $30.4 \%$ had new postoperative thigh numbness, dysesthesias, pain, or weakness. ${ }^{35}$ Twenty-five percent of the patients treated with LIF in the study by Tormenti et al. had postoperative motor radiculopathies, and $75 \%$ experienced postoperative thigh dysesthesias/ paresthesias. ${ }^{33}$ Furthermore, Isaacs et al. found that $33.6 \%$ of patients had postoperative weakness-a single motor grade decrease in 28 patients (resolved in $82 \%$ of cases within 1 year), 2 grades in 6 patients (fully resolved by final follow-up), and more than 2 grades in 3 patients. ${ }^{16}$ One patient had $1 / 5$ proximal muscle weakness that was attributed to a lumbar plexus injury; by the 6-month follow-up visit, the muscle strength had improved to $4 / 5 .^{16}$

Despite these complications, HRQoL scores for both groups in our study improved significantly. The VAS scores for leg and back pain obtained 2 years postoperatively were were significantly lower than preoperative values. Additionally, the ODI scores decreased on average by more than 15 points, which surpassed the minimum clinically important difference previously demonstrated for ODI scores (12.8 points) in ASD. ${ }^{21}$ Previous reports on ASD patients treated with or without LIF have also demonstrated consistent improvement in VAS pain and disability scores after surgery. ${ }^{1-4,8,23,31-33}$ Interestingly, despite not having as robust coronal and sagittal radiographic deformity correction as the LS+Apex group, the LS-Only group had similar 2-year HRQoL scores.

This study has limitations. First and foremost, the sample sizes in each group are small, making the study underpowered to detect important differences between the groups. Selection bias may also jeopardize the generalizability of the results. Despite case-matching and stringent inclusion and exclusion criteria, the deformities treated in each group were on average relatively similar, but individually variable. Despite this variability, the patients were treated with similar surgical techniques, except for the use of multilevel LIF in the LS+Apex group. Thus, our data represent outcomes of the use of these different techniques for variable deformities and do not provide insight into the type of deformity that should be addressed with either of the techniques. Nevertheless, while our operative and postoperative intergroup differences are likely meaningful, they should be carefully considered in the setting of our retrospective evaluation of 2 heterogeneous multicenter databases, which introduce variability in surgical technique (i.e., type of interbody cages-straight or lordotic, number of Smith-Petersen osteotomies), training and experience of surgeons and assistants, efficiency of operating room staff, intraoperative hospital services, and postoperative activity protocols and pain medication regimens. While all of these variables may have influenced operative time, EBL, LOS, and complication rates, it is a real possibility that variations in the abilities of the surgeons performing these techniques, rather than techniques used, may be a significant driver of the outcomes and complications. However, in a multicenter study surgeon variability is randomly distributed across study sites. The variation in use of ALIF or TLIF may also have been a confounder 
in the study given the differences in their cage/graft footprints. Outcome measures may have also been influenced by other patient factors that were not evaluated, including psychological distress. As our sample sizes precluded comparing outcomes between subcategories of patients based on degree of sagittal or coronal deformity (SVA, lumbopelvic mismatch, coronal balance), we suggest that this be an avenue for future investigation. Furthermore, our outcome measures were not comprehensive, as a disease-specific questionnaire, patient satisfaction scores, and a cost analysis were not included. Additionally, we are not able to comment on preoperative curve flexibility and/or loss of deformity correction or complications that occur more than 2 years after surgery, including pseudarthrosis rates.

\section{Conclusions}

Long open posterior instrumented fusions with or without multilevel LIF are used to treat a variety of coronal and sagittal adult thoracolumbar deformities. The addition of multilevel LIF to open PSF with L5-S1 interbody support in this small cohort of patients was often used in cases of more severe coronal and/or sagittal deformities and offered better correction of major Cobb angles, lumbopelvic parameters, and SVA than posterior-only operations. These advantages came at the expense of significantly more major complications, more leg weakness, greater EBL, and longer operative times and hospital stays without an improvement in 2-year outcomes. Future investigations should aim to more clearly define which adult spinal deformities may benefit from the addition of multilevel LIF to open PSF and L5-S1 interbody fusion.

\section{References}

1. Acosta FL, Liu J, Slimack N, Moller D, Fessler R, Koski T: Changes in coronal and sagittal plane alignment following minimally invasive direct lateral interbody fusion for the treatment of degenerative lumbar disease in adults: a radiographic study. J Neurosurg Spine 15:92-96, 2011

2. Anand N, Baron EM, Thaiyananthan G, Khalsa K, Goldstein TB: Minimally invasive multilevel percutaneous correction and fusion for adult lumbar degenerative scoliosis: a technique and feasibility study. J Spinal Disord Tech 21:459467, 2008

3. Anand N, Rosemann R, Khalsa B, Baron EM: Mid-term to long-term clinical and functional outcomes of minimally invasive correction and fusion for adults with scoliosis. Neurosurg Focus 28(3):E6, 2010

4. Bridwell KH, Glassman S, Horton W, Shaffrey C, Schwab F, Zebala LP, et al: Does treatment (nonoperative and operative) improve the two-year quality of life in patients with adult symptomatic lumbar scoliosis: a prospective multicenter evidence-based medicine study. Spine (Phila Pa 1976) 34:2171-2178, 2009

5. Caputo AM, Michael KW, Chapman TM, Jennings JM, Hubbard EW, Isaacs RE, et al: Extreme lateral interbody fusion for the treatment of adult degenerative scoliosis. J Clin Neurosci 20:1558-1563, 2013

6. Carreon LY, Puno RM, Dimar JR II, Glassman SD, Johnson JR: Perioperative complications of posterior lumbar decompression and arthrodesis in older adults. J Bone Joint Surg Am 85-A:2089-2092, 2003

7. Cho KJ, Suk SI, Park SR, Kim JH, Kim SS, Choi WK, et al: Complications in posterior fusion and instrumentation for degenerative lumbar scoliosis. Spine (Phila Pa 1976) 32:2232-2237, 2007

8. Dakwar E, Cardona RF, Smith DA, Uribe JS: Early outcomes and safety of the minimally invasive, lateral retroperitoneal transpsoas approach for adult degenerative scoliosis. Neurosurg Focus 28(3):E8, 2010

9. Daubs MD, Lenke LG, Cheh G, Stobbs G, Bridwell KH: Adult spinal deformity surgery: complications and outcomes in patients over age 60. Spine (Phila Pa 1976) 32:22382244, 2007

10. Deukmedjian AR, Dakwar E, Ahmadian A, Smith DA, Uribe JS: Early outcomes of minimally invasive anterior longitudinal ligament release for correction of sagittal imbalance in patients with adult spinal deformity. ScientificWorldJournal 2012:789698, 2012

11. Deukmedjian AR, Le TV, Baaj AA, Dakwar E, Smith DA, Uribe JS: Anterior longitudinal ligament release using the minimally invasive lateral retroperitoneal transpsoas approach: a cadaveric feasibility study and report of 4 clinical cases. J Neurosurg Spine 17:530-539, 2012

12. Dwyer AF: Experience of anterior correction of scoliosis. Clin Orthop Relat Res (93):191-206, 1973

13. Fairbank JC, Pynsent PB: The Oswestry Disability Index. Spine (Phila Pa 1976) 25:2940-2952, 2000

14. Fujita T, Kostuik JP, Huckell CB, Sieber AN: Complications of spinal fusion in adult patients more than 60 years of age. Orthop Clin North Am 29:669-678, 1998

15. Gupta MC: Degenerative scoliosis. Options for surgical management. Orthop Clin North Am 34:269-279, 2003

16. Isaacs RE, Hyde J, Goodrich JA, Rodgers WB, Phillips FM: A prospective, nonrandomized, multicenter evaluation of extreme lateral interbody fusion for the treatment of adult degenerative scoliosis: perioperative outcomes and complications. Spine (Phila Pa 1976) 35 (26 Suppl):S322-S330, 2010

17. Kaneda K, Shono Y, Satoh S, Abumi K: New anterior instrumentation for the management of thoracolumbar and lumbar scoliosis. Application of the Kaneda two-rod system. Spine (Phila Pa 1976) 21:1250-1262, 1996

18. Kim YB, Lenke LG, Kim YJ, Kim YW, Blanke K, Stobbs G, et al: The morbidity of an anterior thoracolumbar approach: adult spinal deformity patients with greater than five-year follow-up. Spine (Phila Pa 1976) 34:822-826, 2009

19. Knight RQ, Schwaegler P, Hanscom D, Roh J: Direct lateral lumbar interbody fusion for degenerative conditions: early complication profile. J Spinal Disord Tech 22:34-37, 2009

20. Le TV, Vivas AC, Dakwar E, Baaj AA, Uribe JS: The effect of the retroperitoneal transpsoas minimally invasive lateral interbody fusion on segmental and regional lumbar lordosis. ScientificWorldJournal 2012:516706, 2012

21. Liu S, Schwab F, Smith JS, Klineberg E, Ames CP, Mundis $\mathrm{G}$, et al: Likelihood of reaching minimal clinically important difference in adult spinal deformity: a comparison of operative and nonoperative treatment. Ochsner J 14:67-77, 2014

22. Manwaring JC, Bach K, Ahmadian AA, Deukmedjian AR, Smith DA, Uribe JS: Management of sagittal balance in adult spinal deformity with minimally invasive anterolateral lumbar interbody fusion: a preliminary radiographic study. J Neurosurg Spine 20:515-522, 2014

23. Mundis GM, Akbarnia BA, Phillips FM: Adult deformity correction through minimally invasive lateral approach techniques. Spine (Phila Pa 1976) 35 (26 Suppl):S312-S321, 2010

24. Ozgur BM, Aryan HE, Pimenta L, Taylor WR: Extreme Lateral Interbody Fusion (XLIF): a novel surgical technique for anterior lumbar interbody fusion. Spine J 6:435-443, 2006

25. Paulus MC, Kalantar SB, Radcliff K: Cost and value of spinal deformity surgery. Spine (Phila Pa 1976) 39:388-393, 2014

26. Rodgers WB, Gerber EJ, Patterson J: Intraoperative and early 
postoperative complications in extreme lateral interbody fusion: an analysis of 600 cases. Spine (Phila Pa 1976) 36:2632,2011

27. Russo A, Bransford R, Wagner T, Lee M, Chapman J: Adult degenerative scoliosis insights, challenges, and treatment outlook. Curr Orthop Pract 19:357-365, 2008

28. Shamji MF, Isaacs RE: Anterior-only approaches to scoliosis. Neurosurgery 63 (3 Suppl):139-148, 2008

29. Silva FE, Lenke LG: Adult degenerative scoliosis: evaluation and management. Neurosurg Focus 28(3):E1, 2010

30. Smith JA, Deviren V, Berven S, Bradford DS: Does instrumented anterior scoliosis surgery lead to kyphosis, pseudarthrosis, or inadequate correction in adults? Spine (Phila Pa 1976) 27:529-534, 2002

31. Smith JS, Shaffrey CI, Berven S, Glassman S, Hamill C, Horton W, et al: Improvement of back pain with operative and nonoperative treatment in adults with scoliosis. Neurosurgery 65:86-94, 2009

32. Smith JS, Shaffrey CI, Berven S, Glassman S, Hamill C, Horton W, et al: Operative versus nonoperative treatment of leg pain in adults with scoliosis: a retrospective review of a prospective multicenter database with two-year follow-up. Spine (Phila Pa 1976) 34:1693-1698, 2009

33. Tormenti MJ, Maserati MB, Bonfield CM, Okonkwo DO, Kanter AS: Complications and radiographic correction in adult scoliosis following combined transpsoas extreme lateral interbody fusion and posterior pedicle screw instrumentation. Neurosurg Focus 28(3):E7, 2010

34. Uribe JS, Smith DA, Dakwar E, Baaj AA, Mundis GM, Turner AWL, et al: Lordosis restoration after anterior longitudinal ligament release and placement of lateral hyperlordotic interbody cages during the minimally invasive lateral transpsoas approach: a radiographic study in cadavers. J Neurosurg Spine 17:476-485, 2012

35. Wang MY, Mummaneni PV: Minimally invasive surgery for thoracolumbar spinal deformity: initial clinical experience with clinical and radiographic outcomes. Neurosurg Focus 28(3):E9, 2010

36. Youssef JA, McAfee PC, Patty CA, Raley E, DeBauche S, Shucosky E, et al: Minimally invasive surgery: lateral approach interbody fusion: results and review. Spine (Phila Pa 1976) 35 (26 Suppl):S302-S311, 2010

37. Youssef JA, Orndorff DO, Patty CA, Scott MA, Price HL, Hamlin LF, et al: Current status of adult spinal deformity. Global Spine J 3:51-62, 2013

38. Zheng F, Cammisa FP Jr, Sandhu HS, Girardi FP, Khan SN: Factors predicting hospital stay, operative time, blood loss, and transfusion in patients undergoing revision posterior lumbar spine decompression, fusion, and segmental instrumentation. Spine (Phila Pa 1976) 27:818-824, 2002

\section{Disclosures}

Funding for the International Spine Study Group Foundation (ISSGF), through which this study was conducted, was provided by research grants from DePuy Spine and individual donations. Dr. Mundis reports consultant relationships with NuVasive, K2M, and Misonix, and a patent holder relationship with K2M. Dr. Okonkwo reports receiving royalties from Biomet. Dr. Mummaneni reports a consultant relationship with and receipt of royalties from DePuy; direct stock ownership in Spinicity/ISD; receipt of royalties from Taylor and Francis Group, Springer, and Thieme (publishers); and receipt of honoraria from AOSpine. Dr. Smith reports consultant relationships with Zimmer Biomet, NuVasive, and Cerapedics; clinical or research support from DePuy Synthes and NuVasive for the study described; support of non-studyrelated clinical or research effort by DePuy Synthes; and receipt of royalties from Zimmer Biomet. Dr. Shaffrey reports consultant relationships with Zimmer Biomet, Medtronic, and NuVasive; direct stock ownership in NuVasive; patent holder relationships with Zimmer Biomet, Medtronic, and NuVasive; and receipt of support for this study from DePuy Synthes to the ISSGF. Dr. Fessler reports an ownership interest in InQ Innovations, a consultant relationship with DePuy Synthes and Benvenue, and patent holder relationships with DePuy Synthes, Medtronic Sofamor Danek, and Stryker. Dr. Bess reports consultant relationships with K2 Medical, NuVasive, and AlloSource; patent holder relationships with K2 Medical and Innovasis; support for the study described from DePuy Spine; and support for non-studyrelated clinical or research efforts from Medtronic, NuVasive, K2 Medical, Innovasis, and Stryker. Dr. Schwab reports direct stock ownership in Nemaris Inc.; a consultant relationship with Zimmer Biomet, K2M, MSD, Medicrea, and NuVasive and royalty payments or potential future royalty income from those companies due to development activities; and support of non-study-related clinical or research efforts from SRS, AO, and DePuy Spine (paid through ISSGF). Dr. Burton reports a consultant relationship with, a patent holder relationship with, and receipt of support for the study described from DePuy Spine. Dr. Hart reports a consultant relationship with DePuy Synthes and Globus; a patent holder relationship with Oregon Health \& Science University; support of non-study-related clinical or research effort from ISSGF and Medtronic; and receipt of royalties and/or honoraria from SeaSpine, DePuy Synthes, and Globus. Dr. Deviren reports a consultant relationship with NuVasive and Guidepoint and receipt of royalties from NuVasive. Dr. Ames reports a consultant relationship with DePuy, Stryker, and Medtronic; a patent holder relationship with Fish \& Richardson, P.C.; and receipt of royalties from Biomet Spine and Stryker.

\section{Author Contributions}

Conception and design: Theologis, Deviren, Ames. Acquisition of data: Theologis. Analysis and interpretation of data: Theologis, Deviren, Ames. Drafting the article: Theologis. Critically revising the article: all authors. Reviewed submitted version of manuscript: all authors. Approved the final version of the manuscript on behalf of all authors: Theologis. Statistical analysis: Nguyen. Administrative/technical/material support: Mundis, Okonkwo, Mummaneni, Smith, Shaffrey, Fessler, Bess, Schwab, Diebo, Burton, Hart, Deviren, Ames. Study supervision: Okonkwo, Mummaneni, Smith, Shaffrey, Fessler, Bess, Schwab, Diebo, Burton, Hart, Deviren, Ames.

\section{Supplemental Information \\ Previous Presentations}

Portions of this work were presented as an oral presentation at the 8th Annual SOLAS Research Meeting, San Diego, California, April 18, 2015.

\section{Correspondence}

Alexander Theologis, Department of Orthopaedic Surgery, University of California, San Francisco, 500 Parnassus Ave., MU West 3rd Fl., San Francisco, CA 94143.email: alekos.theologis@ ucsf.edu. 